\title{
SEGURANÇA DO TRABALHO EM UMA ESCOLA PRIMÁRIA: ERGONOMIA PARA FUNCIONÁRIOS E SEGURANÇA PARA CRIANÇAS
}

\section{SECURITY OF WORK IN A PRIMARY SCHOOL: ERGONOMICS FOR EMPLOYEES AND SECURITY FOR CHILDREN}

\author{
Carolina Gomes de Melo', Elson Mendonça Felici ${ }^{2}$ \\ 1 Universidade do Oeste Paulista - UNOESTE, Curso de Engenharia Ambiental e \\ Sanitária. Presidente Prudente, SP. \\ e-mail: elson@unoeste.br
}

RESUMO - A ergonomia visa um maior benefício para a saúde e bem estar dos colaboradores nos locais de trabalho. Nesse sentido, o presente estudo tem como objetivos apresentar o diagnóstico atual de uma Escola Municipal de Educação Infantil e Fundamental, com relação à ergonomia e segurança do trabalho. Objetiva-se ainda levantar os principiais problemas encontrados e elaborar propostas de melhoria para a realização de atividades. A metodologia se dá através do uso de abordagens qualitativa e quantitativa; a primeira serve como apoio para determinar a qualidade do mobiliário escolar, dos equipamentos de segurança presentes dentro do ambiente escolar e também das ferramentas disponíveis; já a segunda abordagem aponta a quantidade e quais objetos precisam de reforma ou de novas aquisições. $O$ trabalho é classificado como estudo de caso, visando à investigação do ambiente escolar, apontando defeitos e problemas e a busca pelas possíveis soluções para os mesmos. Os resultados mostraram problemas relacionados à questão ergonômica e outros ligados a riscos de acidentes com crianças e colaboradores. Assim, espera-se que com a implantação das propostas de melhoria, seja possível fornecer aos funcionários e alunos um ambiente escolar mais saudável e com menores riscos de acidentes ou outros tipos de problemas ergonômicos.

Palavras-chave: ergonomia; segurança do trabalho; ambiente de trabalho; escola; funcionários; crianças.

Recebido em: 08/08/2017

Revisado em: 02/10/2017

Aprovado em: 05/10/2017
ABSTRACT - Ergonomics aims at a greater benefit to the health and well-being of employees in the workplace. In this sense, the present study aims to present the current diagnosis of a Municipal School of Infant and Elementary Education, in relation to ergonomics and work safety. It also aims to raise the main problems encountered and develop proposals for improvement to carry out activities. The methodology is given through the use of qualitative and quantitative approaches; The first serves as support to determine the quality of school furniture, safety equipment present within the school environment and also the tools available; The second approach points to quantity and which objects need reform or new acquisitions. The work is classified as a case study, aiming at the investigation of the school environment, pointing out defects and problems and the search for possible solutions for them. The results showed problems related to the ergonomic issue and others related to the risk of accidents with children and employees. Thus, it is expected that with the 
implementation of improvement proposals, it will be possible to provide employees and students with a healthier school environment and with less risk of accidents or other types of ergonomic problems.

Keywords: ergonomics; labor safety; workplace; school; employees; children. 


\section{INTRODUÇÃO}

Entende-se que desde o surgimento dos locais de trabalho, sejam eles grandes fábricas e indústrias ou pequenos escritórios, a ergonomia e a segurança - para todas as pessoas que convivem nestes ambientes mesmo que de forma mínima e mais simples, sempre se fizeram presentes para um ambiente mais seguro e também mais eficaz de trabalho, obtendo-se uma motivação maior para o desempenho e desenvolvimento das atividades atribuídas a cada função e a cada um dos funcionários.

A ergonomia e a segurança do trabalho andam sempre juntas, trazendo um maior benefício para a saúde dos colaboradores e para todas as pessoas que são necessárias nos locais de trabalho. A falta de um ambiente mais ergonômico e mais seguro acarreta em uma série de desvantagens, como a exposição a acidentes de trabalho e também a doenças irreversíveis. A aplicação de ferramentas e de conceitos desta grande área só tende a trazer benefícios para todos, da camada mais alta à camada mais baixa da organização, sendo necessária uma boa conscientização de todos.

Como objeto de estudo, a ergonomia (ou também Engenharia dos Fatores Humanos) é uma grande área que tem se mostrado cada dia mais importante pelo fato de cuidar da saúde de um colaborador dentro de seu ambiente de trabalho, fazendo com que este se adeque a suas necessidades. Os conceitos e aplicações da ergonomia trazem uma enorme quantidade de benefícios a todos os envolvidos, resultando em um local mais apto a realização de atividades trabalhistas e de caráter mais seguro, facilitando o modo como todo o trabalho é realizado dentro do ambiente.

O presente trabalho apresenta como objeto de estudo a aplicação de normas reguladoras, a obtenção e/ou manutenção de móveis dentro do prédio que permitam a correta execução de atividades de trabalho, visando uma postura perfeita, evitando a ocorrência de possíveis dores e também a obtenção de materiais e equipamentos de segurança que permitirão ao colaborador o uso em caso de emergências dentro do ambiente de trabalho, em uma escola primária municipal.

A pesquisa visa soluções no que se refere ao ambiente de trabalho dentro de uma escola primária. Dentre os principais problemas de pesquisa, destacam-se: o ambiente é seguro para os funcionários exercerem as atividades designadas? As normas de segurança estão aplicadas dentro do espaço físico? O prédio apresenta as principais ferramentas de segurança? 0 investimento necessário condiz com as condições da mantenedora? O mobiliário utilizado está adequado? 
A justificativa para este estudo se dá pelo crescente aumento das fábricas e instalações de trabalho, que trazem uma preocupação com a saúde do colaborador e a forma como o mesmo exerce suas atividades dentro do ambiente. Sendo assim, a importância de se estudar e de aplicar seus conceitos está cada vez mais presente, se fazendo essencial e de extrema importância dentro dos ambientes de trabalho, preservando a integridade, saúde e segurança das pessoas que ali se fazem presentes, prestando suas contribuições e realizando suas atividades.

\section{OBJETIVO}

O objetivo geral da pesquisa é diagnosticar a situação atual da escola em relação à ergonomia e segurança do trabalho. Apontam-se como objetivos específicos o levantamento dos principais problemas relacionados à ergonomia e a riscos de acidentes no ambiente escolar; a comparação entre os dados encontrados referentes ao mobiliário e a legislação aplicável; e a proposição de medidas a serem adotadas para proteger a saúde e segurança dos funcionários e alunos.

\section{MÉTODO DE ANÁLISE}

O universo de estudo foi uma Escola Municipal de Educação Infantil e Fundamental, com capacidade para 700 crianças, se dividindo em dois períodos: matutino e vespertino, com cinco salas para crianças de Pré I, outras cinco salas de Pré II (educação infantil) e mais quatro salas para crianças de 1을 Ano (ensino fundamental), totalizando quatorze salas em cada período. Somando os dois períodos, a quantidade de alunos que a escola é capaz de atender é de aproximadamente 700 crianças, sendo que no presente ano o número de alunos frequentes é de cerca de 650 crianças.

O trabalho fez uso de técnica de observação, utilização da revisão de literatura, uso de abordagens qualitativa e quantitativa. Ao se tratar da questão quantitativa, o estudo permitiu determinar o número de equipamentos e ferramentas que se fez necessário dentro deste ambiente para que o mesmo se adequasse às normas e padrões exigidos, pois Denzin (2006) considera que em relação aos estudos organizacionais, a pesquisa quantitativa permite a mensurar opiniões, reações, hábitos e atitudes dentro de um universo, por meio de amostras que o represente estatisticamente. Ja no que diz respeito à abordagem qualitativa, Segundo os estudos de Bryman (1989) a pesquisa usou parâmetros relacionados à qualidade. As reuniões e discussões em grupo permitiram que a satisfação e/ou insatisfação dos colaboradores fossem reveladas, suas opiniões e o que os mesmos achavam que 
precisava ser mudado para a melhora do espaço físico, resultando em uma melhor relação com o ambiente de trabalho, de forma a melhorar a execução das atividades, resultando em um melhor desempenho e um maior comprometimento dos mesmos com suas atividades e também com todos a sua volta.

A observação do espaço físico, dos móveis e dos utensílios de segurança já existentes dentro do ambiente também esteve presente como forma de investigação, permitindo uma maior e melhor visualização da atual situação e do que precisou ser melhorado para que se obtivesse ergonomia e segurança, resultando na melhor execução de atividades e também em uma maior segurança para todos os colaboradores e todos os alunos presentes na escola.

Por fim, considerando as observações em campo e a legislação aplicável, foram elaboradas propostas de ajustes e melhorias no mobiliário, nas dependências do ambiente escolar e também na execução dos serviços, objetivando a melhoria da qualidade de vida dos colaboradores e alunos.

\section{RESULTADOS}

Com relação à forma de análise dos resultados, todos os dados coletados foram trabalhados usando a forma descritiva, que permitiu que estas informações obtidas com a pesquisa bibliográfica, com a observação e com as entrevistas fossem estudadas e analisadas. Estes resultados permitiram a aplicação de conceitos, de ferramentas e de métodos que envolvem a ergonomia e a segurança do trabalho, determinando assim, o que foi útil e o que foi necessário ser aplicado dentro da escola municipal.

Todos estes dados permitiram a elaboração de propostas necessárias para melhorar a execução das atividades e funções trabalhistas e também propostas relacionadas ao ajustes, compra ou manutenção do mobiliário existente na escola, bem como visando a qualidade de vida e bem estar de todos.

\section{DISCUSSÕES}

Os resultados encontrados dentro da escola com a intenção de fazer o diagnóstico atual do ambiente escolar no que diz respeito à ergonomia e segurança do trabalho incluindo a apresentação de conceitos, ferramentas, equipamentos, normas e aplicações -, servem para determinar medidas necessárias para a proteção e segurança dos funcionários e alunos, apresentar benefícios da correta gestão da ergonomia e da segurança do trabalho e o apontamento da necessidade de se ter um ambiente seguro e apto para a saúde dos colaboradores usando a técnica de observação para ressaltar os objetos necessários de mudança. 
O estudo propôs fazer a descrição da empresa e os problemas encontrados dentro do ambiente escolar e quais medidas são necessárias para que os problemas sejam melhorados ou extintos.

\section{CONCLUSÃO}

Através do uso de técnicas apresentadas na metodologia - técnica de observação, utilização da revisão de literatura, uso de abordagens qualitativa e quantitativa -, foi-se capaz de realizar o diagnóstico atual da escola com relação à ergonomia e segurança do trabalho, apontando problemas relacionados a estas duas áreas da Engenharia de Produção e riscos de acidentes dentro do ambiente escolar, comparando ainda dados encontrados referentes ao mobiliário e a legislação aplicável; e também à proposição de medidas a serem adotadas para proteger a saúde e segurança dos funcionários e alunos e ainda propiciar a apresentação de conceitos, ferramentas e materiais que envolvem ambas as áreas e a importância das mesmas dentro dos ambientes de trabalho.

Com o diagnóstico atual da escola, vêse que a mesma encontra alguns problemas em estar de acordo com normas que atuam na área de segurança do trabalho, tendo que melhorar a questão de equipamentos de proteção coletiva, sendo necessária a aquisição de novos tipos de equipamentos - extintores de incêndio, placas de saída de emergência - este primeiro já em negociação para aquisição por parte da empresa mantenedora.

Com o levantamento dos principais problemas presentes no ambiente escolar, foi possível elaborar algumas propostas de melhoria, buscando alcançar uma ambiente laboral mais saudável e com menores riscos de acidentes. As propostas incluíam os ajustes no mobiliário; a troca do bebedouro e do parque escolar; a eliminação dos bancos de concreto e substituição por modelos de plástico; a retirada dos vasos de plantas e a aquisição dos equipamentos de proteção. Entende-se que todas as propostas apresentadas são viáveis do ponto de vista econômico e operacional.

Nos dias de hoje, com todo o crescimento industrial que vem acontecendo, deve-se fixar a importância destes ambientes de trabalho preparados para a execução de atividades e funções e fazer a sua adequação as necessidades de colaboradores e funcionários, bem como sua conscientização e treinamento para uso correto destes locais de trabalho, resultando na correta execução destas atividades e funções propostas e no manuseio de máquinas, equipamentos e ferramentas que se fazem necessários.

Por fim espera-se que com a implantação dessas propostas de melhoria, seja possível fornecer aos funcionários e 
alunos um ambiente escolar mais saudável e com menores riscos de acidentes ou outros tipos de problemas ergonômicos.

\section{REFERÊNCIAS}

ABERGO. 2000. Disponível em:

<http://www.abergo.org.br/>. Acesso em: 10 out. 2016.

http://www.unesco.org. Acesso em: 01 ago. 2015.

COUTO, H. A. Ergonomia aplicada ao trabalho. São Paulo: Ergo, 2007.

DENZIN, N. K.; LINCOLN, Y. S. Handbook of Qualitative Research. Thousand Oaks: Sage, 2005. 